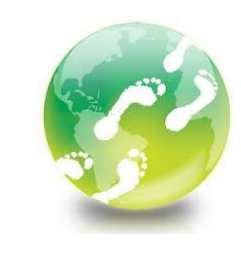

\section{Jurnal Teknologi Kimia Unimal}

homepage jurnal: https://ojs.unimal.ac.id/jtk
Jurnal

Teknologi

Kimia

Unimal

\title{
APLIKASI KONTROL PID PADA OUTLET GAS UNIT SLUG CATCHER METODE INTERFACING HYSYS-MATLAB
}

\author{
Dara Sabhira NN, Nasrul Z.A, Muhammad \\ Jurusan Teknik Kimia, Fakultas Teknik, Universitas Malikussaleh \\ Kampus Utama Cot Teungku Nie Reuleut, Muara Batu, Aceh Utara - 24355 \\ Korespondensi: 082164699680,nasrulza@unimal.ac.id
}

\begin{abstract}
Abstrak
Penelitian Kontrol Proportional - Integral (PI) adalah kontroller yang berfungsi menentukan presisi suatu sistem instrumentasi dengan karakteristik adanya umpan balik pada sistem tersebut (feed back). slug catcher adalah sebuah alat pemisah digunakan untuk memisahkan lumpur, lendir, minyak, air dan gas yang berasal dari wellpad. Metodologi penelitian ini adalah membuat model steady state slug catcher, lalu mengubah model steady state menjadi model dynamic, lalu membuat model kontrol PI, setelah itu melakukan tuning terhadap kontrol PI dan melakukan pengujian terhadap kontrol PI, dengan cara memberi gangguan pada set point. Penelitian ini bertujuan untuk mendapatkan waktu respon tercepat terhadap gangguan tekananan serta mendapatkan variable Kc dan Ti terbaik. Hasil dari penelitian pengaplikasian sistem kontrol PI didapatkan waktu tercepat yaitu 0.1 menit dengan nilai $\mathrm{Kc}=1$, dan Ti=0.01. Pada suhu 85.31oC dengan tekanan $4238 \mathrm{kPa}$ dengan laju alir 339.62 MMSCFD. Sedangkan waktu terlama pada hasil pengujian kontrol PID dengan mengubah tekanan menjadi $4270 \mathrm{kPa}$, yaitu 2.8 menit dengan nilai $K c=1.07$, dan nilai $T i=0.04$.
\end{abstract}

Kata kunci: Slug Catcher, PI, Steady State, Dynamic, Set Point, OP

\section{Pendahuluan}

Definis pengendalian proses adalah "cara memperoleh" keadaan proses agar sesuai dengan yang diinginkan. Pengendalian proses ini bertujuan menjaga nilai variabel proses agar tetap memiliki nilai yang sama dengan setpoint. Akan tetapi tujuan tersebut sulit dipenuhi dikarenakan keterbatasan operasi dan kemampuan sistem pengendalian. Oleh karena itu, tujuan praktis atau tujuan nyata pengendalian proses yaitu mempertahankan nilai variabel proses tetap berada disekitar nilai yang diinginkan. Namun perlu diingat bahwa hakikat utama pengendalian proses dalam industri adalah untuk memperoleh hasil akhir proses 
produksi agar sesuai target. Makna dari pernyataan ini adalah, satu atau beberapa nilai variabel proses mungkin perlu dikorbankan untuk mencapai tujuan yang lebih besar yaitu hasil akhir proses produksi ( Heriyanto, 2010)

PID (proporsional, integral, dan turunan) adalah sebuah pengontrol yang menyertakan elemen dengan tiga fungsi tersebut. Dalam literatur yang menjelaskan tentang PID, disebutkan bahwa pengontrol juga digunakan pada level elemen: yang disebut dengan "elemen P", "I elemen", dan turunannya elemen sebagai "D elemen. Berdasarkan pengumpulan data pada tahun 1989 di Jepang membuktikan sebanyak $90 \%$ dari pengendali pada industri proses adalah pengendali PID serta versi lanjutan dari kontroler PID (Araki, 2002)

PID adalah jenis pengendali yang paling populer. Pengendali PID adalah pengendali konvensional dan masih sering digunakan pada dunia industri. Proses perancangan dan realisasi yang tidak terlalu susah sehingga implementasinya masih terus berkembang, menyebabkan pengendali PID masih dapat bertahan hingga saat ini (Pratomo, 2012)

Hasil pengontrol Derivative memiliki sifat seperti halnya suatu operasi differensial. Perubahan yang mendadak pada masukan pengontrol, akan mengakibatkan perubahan yang sangat besar dan cepat. Gambar 1 menunjukkan blok diagram yang menggambarkan hubungan antara sinyal kesalahan dengan keluaran pengontrol (Skogestad \& Grimholt, 2011)

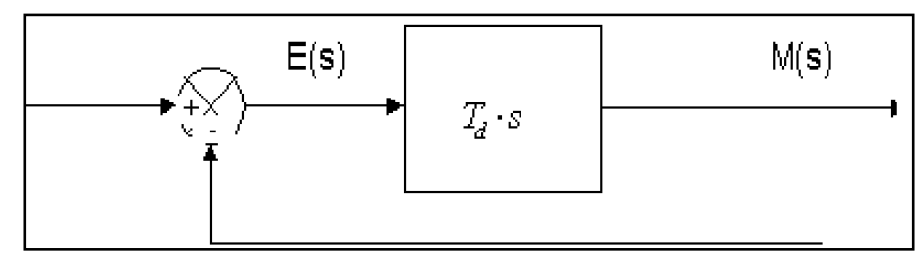

Gambar 1 Diagram Pengontrol Derivative

Output dari Proportional Integral Derivative controller dinyatakan dengan persamaan 1dibawah ini:

$$
\mathrm{OP}_{(\mathrm{t})}=\mathrm{OP}_{\mathrm{ss}}+\mathrm{K}_{\mathrm{c}} \cdot \mathrm{E}(\mathrm{t})+\frac{K_{c}}{T_{i}} \int \mathrm{E}(\mathrm{t}) \cdot \mathrm{dt}+\mathrm{K}_{\mathrm{c}} \cdot \mathrm{T}_{\mathrm{d}}+\frac{d E(t)}{d t}
$$


Derivative action mampu memperkirakan dan mengantisipasi error atau deviasi. Respon lambat yang diakibatkan penambahan integral term dapat diatasi dengan derivative action maka respon akan lebih cepat (Taryono, 2009).

Sistem kerja PID controller ini yaitu apabila pada proses memiliki kesalahan yang sangat besar, maka controller PI akan memerlukan waktu yang panjang untuk mencapai set point-nya, tetapi untuk controller PID akan mempercepat proses pencapaian set point tersebut (Haryono, 2007)

"P" bekerja sebagai pemberi lonjakan pada present value untuk bergerak mendekati set point, "I" bekerja sebagai yang merapatkan antara present value dengan set point sedangkan D bekerja sebagai pemendek waktu respon. Hal inilah yang menyebabkan PID Controller akan bekerja untuk control yang memiliki respon yang lambat. Sedangkan PI Controller akan bekerja untuk control yang memiliki respon yang cepat.

Untuk mendapatkan hasil yang maksimal pada kerja pengontrol diperlukan nilai batas minimum dan maksimum. Batas ini yang akan memberi batas pada nilai manipulated variable yang dihasilkan. Komponen PID terdiri tiga jenis yaitu Proportional, Integratif, dan Derivative. Ketiganya dapat dipakai tergantung dari respon yang kita inginkan terhadap suatu plant. Tabel 1 menunjukkan parameter dalam melakukan penyetelan (tuning) pada PID (Julie, 2013)

Tabel 1 Parameter Tuning PID

\begin{tabular}{|l|l|l|l|}
\hline Sistem & $\mathrm{K}_{\mathrm{c}}$ & $\mathrm{T}_{\mathrm{i}}$ & $\mathrm{T}_{\mathrm{d}}$ \\
\hline Laju Alir & 0,1 & 0,2 & 0 \\
\hline Tekanan & 2 & 2 & 0 \\
\hline Temperatur & 1 & 20 & 0 \\
\hline Level & 2 & 10 & 0 \\
\hline
\end{tabular}

(Sumber: Julie, 2013)

\section{Bahan dan Metode}

Bahan-bahan dan peralatan yang diperlukan dalam menjalankan penelitian ini antara lain adalah Data actual Slug Catcher Tipe: Slug Catcher (221-D9001), Jenis: Separator 2 fasa, Diameter: 3,015 meter, Lebar : 11,045 meter, Komponen: 
Natural Gas. Laptop Lenovo, Processor intel CORE i3 64-Bit Operating System Software Aspen Hysys V3.2, Software Design Expert V.13 dan Software Matlab 5.2

Penelitian ini terdiri dari dua tahap yaitu pembuatan model steady state dari slug catcher dengan Hysys hingga model convergen. Selanjutnya persiapan untuk masuk ke mode dynamic Hysys. Hal ini dilakukan untuk memastikan sistem siap untuk masuk ke Dynamict tanpa ada indikasi error. Selanjutnya peneliti melanjutkan dengan menyiapkan modul P\&ID di Matlab, kemudian melakukan interfacing Hysys dengan Matlab. Jika interfacing berhasil, maka tahap berikutnya memasukkan nilai $\mathrm{Kc}$, Ti, Td di Matlab. Dalam hal ini $\mathrm{Kc}=2, \mathrm{Ti}=2$, dan $\mathrm{Td}=0$ (Julie, 2013)

Pengujian dilakukan dengan cara mengubah harga setpoint dari matlab, dan amati apakah Present Value mengikuti harga setpoint. Jika Present Value sudah mengikuti harga set point, maka platform sudah siap untuk digunakan untuk penelitian. Jika belum, maka harga Kc, dan Ti perlu diubah hingga kontrol bekerja dengan baik.

Tahap kedua yaitu Rancangan percobaan dilakukan dengan menggunakan aplikasi Design Expert Ver 7.0. RSM dengan model Central Composite Design. RSM dilakukan 3 kali, RSM yang pertama menggunakan $\mathrm{Kc}=1$ dan $\mathrm{Ti}=0.05$. Selanjutnya untuk RSM yang ke dua, menggunakan dasar Kc dan Ti pada Run dengan waktu tercepat dari RSM pertama. Penentuan nilai Kc dan Ti pada RSM yang ke tiga dilakukan dengan cara yang sama pada RSM ke dua. Selanjutnya data dari RSM dengan hasil terbaik ini diolah hingga mendapatkan model matematikanya. Selanjutnya menguji nilai Kc dan Ti terbaik terhadap kemampuan merespon gangguan dengan cara mengubah-ubah setpoint (tekanan) pada bagian atas slug catcher. 


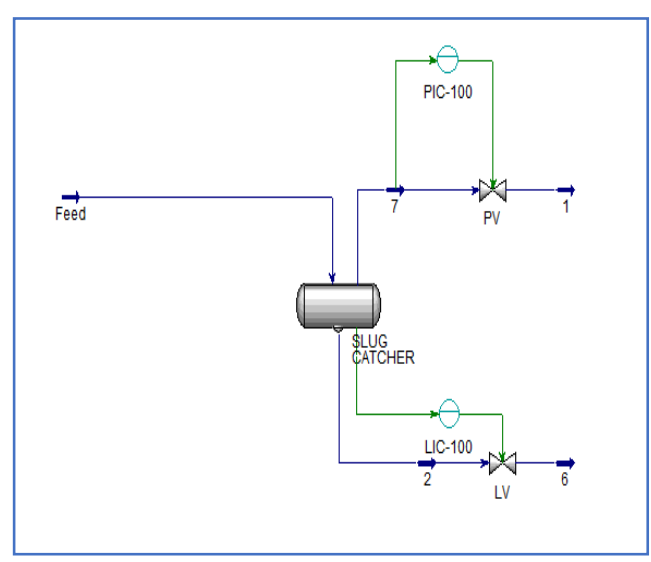

Gambar 2 Platform Penelitian

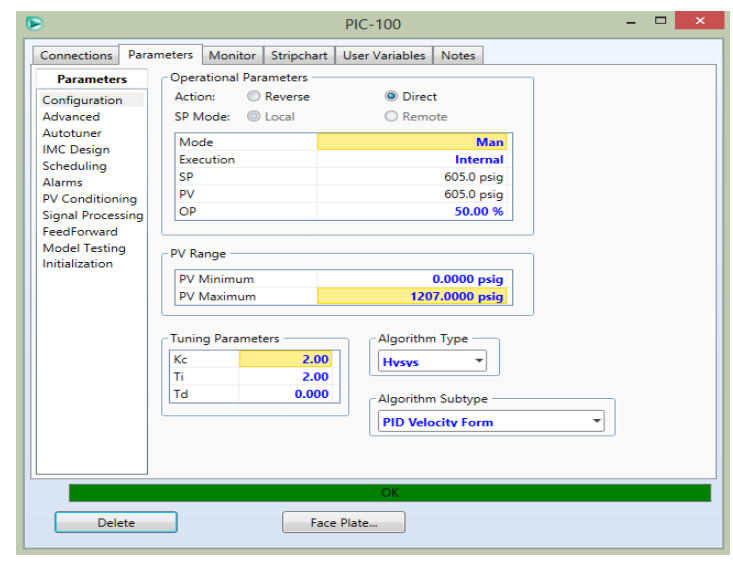

Gambar 3 Setting Platform Penelitian

Gambar 2 merupakan platform penelitian yang akan digunakan pada penelitian ini. Pada gambar 2, bisa dilihat bahwa platform tersebut sudah terpasang kontrol dan sudah menjadi dynamic mode. Setting dan pengisian parameter untuk uji platform dapat dilihat pada Gambar 4. Hasil pengujian dengan mengubah setpoint dari 605 psig ke 610 lalu kembali ke 605 dan turun ke 600, waktu respon yang diperoleh rata-rata 80 menit. Seperti yang terdapat pada Gambar 4

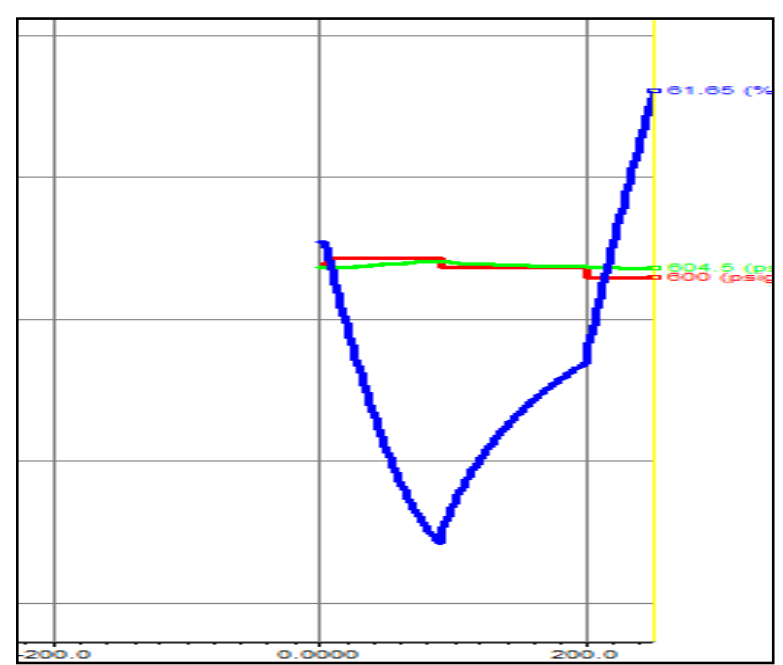

Gambar 4 Respon Controller PIC 100.

Dari hasil diatas, perubahan setpoint (garis merah) dapat diikuti oleh present value (garis hijau) meski waktu responnya masih lama, maka platform penelitian sudah dapat digunakan.

\section{Hasil dan Diskusi}


Penelitian ini dijalankan berdasarkan desain Response Surface Methodology (RSM) yang menggunakan software Design Expert V.13. Hasil penelitian ini berupa waktu tercepat dalam merespon gangguan pada tekanan Slug Catcher (D9001) yang dihasilkan dengan cara mentuning nilai-niali parameter yang telah ditentukan agar didapatkan waktu respon tercepat. Penentuan nilai kc, ti adalah hal yang diperhatikan dalam pengontrolan PI. Nilai-nilai tersebut adalah hal yang sangat berpengaruh terhadap control PI sebagai tolak ukur terhadap kemampuan kontrol bekerja (merespon). Nilai konstanta yang tidak tepat dapat mengakibatkan control tidak bekerja dengan sempurna (Damanik et al., 2020). Nilai parameter Kc dan Ti yang diperoleh dari Response Surface Methodology digunakan untuk mentuning proses kontrol PI sehingga didapat nilai respon yang tercepat.

Tabel 2 Hasil Penelitian RSM 1 Menggunakan Software Design Expert V.13

\begin{tabular}{|c|c|c|c|c|c|}
\hline \multirow{2}{*}{ Run } & \multicolumn{2}{|c|}{ Yariabel Bebas. } & \multicolumn{3}{c|}{ Variabel Terikat } \\
\cline { 2 - 6 } & A:Kc & B:Ti & $\begin{array}{c}\text { Waktu } \\
\text { (menit) }\end{array}$ & $\begin{array}{c}\mathrm{H}_{2} \mathrm{~S} \\
(\mathrm{kgmol} / \mathrm{jam})\end{array}$ & $\begin{array}{c}\mathrm{C} 1 \\
\text { (kgmol/jam) }\end{array}$ \\
\hline 1 & 1.00 & 0.01 & 0.01 & 0.10 & 164.58 \\
\hline 2 & 1.00 & 0.06 & 0.06 & 3.70 & 164.58 \\
\hline 3 & 1.00 & 0.06 & 0.06 & 3.70 & 164.58 \\
\hline 4 & 1.35 & 0.09 & 0.09 & 3.40 & 164.62 \\
\hline 5 & 0.65 & 0.09 & 0.09 & 11.85 & 164.28 \\
\hline 6 & 1.35 & 0.02 & 0.02 & 1.12 & 164.58 \\
\hline 7 & 0.50 & 0.06 & 0.06 & 7.10 & 164.55 \\
\hline 8 & 1.00 & 0.06 & 0.06 & 3.70 & 160.45 \\
\hline 9 & 0.65 & 0.02 & 0.02 & 2.10 & 164.58 \\
\hline 10 & 1.00 & 0.06 & 0.06 & 3.70 & 164.58 \\
\hline 11 & 1.00 & 0.06 & 0.06 & 3.70 & 164.58 \\
\hline 12 & 1.50 & 0.06 & 0.06 & 2.80 & 164.62 \\
\hline 13 & 1.00 & 0.10 & 0.10 & 7.10 & 164.57 \\
\hline
\end{tabular}

Sumber: (Penelitian Aplikasi PI Pressure Control Aspen Hvsvs, 2021)

Pada RSM 1 diperoleh hasil respon tercepat dengan waktu 0.01 menit dengan nilai Kc sebesar 1.00 dan nilai Ti sebesar 0.01. Sedangkan respon terlambat diperoleh pada run ke lima. Respon terlambat pada RSM pertama diperoleh dengan waktu 0.09 menit dengan nilai Kc sebesar 0.65 dan nilai Ti 
sebesar 0.09. Pada penelitian sebelumnya dilakukan satu kali RSM, sedangkan penelitian yang dikerjakan oleh peneliti pada saat ini dilakukan tiga kali RSM.

\subsection{Validasi Simulasi \& Model Berdasarkan Central Composite Design}

Korelasi masing-masing variabel dapat ditentukan mengunakan metode Quadratic. Hasil kalkulasi dari Design Expert V.13 memberikan model estimasi koefisien untuk masing - masing variabel sebagai berikut.

- Waktu RSM 1 = Model Persamaan (Process Order: Quadratic) adalah:

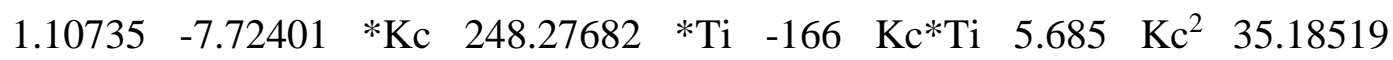
$* \mathrm{Ti}^{2}$

\subsection{Analisa Varian (Anova) Untuk Model Simulasi}

Validnya suatu model yang telah di lakukan pada penelitian ini masih belum memberikan gambaran menyeluruh terhadap signifikasi varibel terkait baik secara individu maupun interaksi antar variabel. Oleh karena itu analisa varian (ANOVA) dilakukan untuk mengevaluasi pengaruh variabel terikat secara individu, Quadratic maupun interaksi pada model yang diusulkan.

Tabel 3 Regresi Statistik

\begin{tabular}{|c|c|c|c|c|c|}
\hline Source & $\begin{array}{c}\text { Std. } \\
\text { Dev. }\end{array}$ & $\mathrm{R}^{2}$ & Adj $^{2}$ & Pred $\mathrm{R}^{2}$ & Keterangan \\
\hline Linear & 1.40 & 0.8208 & 0.7850 & 0.6144 & - \\
\hline 2 FI & 0.7986 & 0.9478 & 0.9303 & 0.8385 & - \\
\hline Quadratic & 0.5611 & 0.9799 & 0.9656 & 0.8574 & Suggested \\
\hline Cubic & 0.2166 & 0.9979 & 0.9949 & 0.8633 & Aliased \\
\hline
\end{tabular}

Sumber: (Penelitian Aplikasi PI Pressure Control Design Expert, 2021)

Hasil analisa varian (ANOVA) model Quadratic pada Tabel 3 telah diperoleh berdasarkan kesesuaian seluruh variabel terikat dengan model jenis Quadratic. Hal ini mengindikasikan bahwa lebih dari $98 \%$ data eksperimen bersesuian dengan hasil prediksi oleh model dan hanya kurang dari $2 \%$ total variasi yang tidak dapat dijelaskan oleh model. 
Tabel 4 Data Analisa Varian (ANOVA)

\begin{tabular}{|c|c|c|c|c|c|c|}
\hline Source & $\begin{array}{c}\text { Sum of } \\
\text { Aquares }\end{array}$ & df & $\begin{array}{c}\text { Mean } \\
\text { Square }\end{array}$ & F Value & $\begin{array}{c}\text { P-value } \\
\text { Prob > F }\end{array}$ & \\
\hline Mode1 & 107.67 & 5 & 21.53 & 68.39 & 0.0001 & significant \\
\hline $\mathrm{A}-\mathrm{Kc}$ & 30.07 & 1 & 30.07 & 95.52 & 0.0001 & \\
\hline $\mathrm{B}-\mathrm{Ti}$ & 60.11 & 1 & 60.11 & 190.93 & 0.0001 & \\
\hline $\mathrm{AB}$ & 13.95 & 1 & 13.95 & 44.30 & 0.0003 & \\
\hline $\mathrm{A}^{2}$ & 3.51 & 1 & 3.50 & 11.15 & 0.01 & \\
\hline $\mathrm{B}^{2}$ & 0.0088 & 1 & 0.0088 & 0.02 & 0.87 & \\
\hline Residual & 2.20 & 7 & 0.3148 & & & \\
\hline Lack offit & 2.20 & 5 & 0.7346 & & & \\
\hline Pure Error & 0.0000 & 4 & 0.0000 & & & \\
\hline Cor Total & 5,5172 & 12 & & & & \\
\hline
\end{tabular}

Sumber: (Penelitian Aplikasi PI Pressure Control Design Expert, 2021)

Pada Tabel 4 nilai probabiliti (Prob > F) untuk seluruh koefisien menunjukkan bahwasanya nilainya lebih kecil dari 0,05 maka koefisien tersebut signifikan atau berpengaruh secara nyata pada ekperimen. Akan tetapi, apabila nilai probabiliti (Prob > F) lebih besar dari 0,1 maka model yang ditunjukkan tidak signifikan. Tabel 2 menunjukkan bahwa model Quadratic pada nilai Kc dan $\mathrm{Ti}$ berpengaruh secara nyata dalam mencapai waktu tercepat dalam merespon gangguan pada pressure pada alat Slug Catcher (D9001). Pada Tabel 4 terlihat signifikan pula. Hal ini menunjukkan bahwa secara statistik variabel bebas terhadap variabel - variabel ini ( $\mathrm{Kc}$ dan $\mathrm{Ti}$ ) memberi pengaruh yang besar terhadap menghasilkan waktu tercepat dalam merespon gangguan. Sehingga variabel - variabel tersebut memberikan pengaruh yang berarti dalam merespon gangguan pada tekanan.

\subsection{Regresi Statistik untuk Efisiensi Optimasi terhadap Waktu Respon}

Selanjutnya pada Gambar 5 menunjukkan analisa terhadap model korelasi variabel bebas terhadap variabel terikat. Koefisien korelasi dan standar devias digunakan untuk mengevaluasi model yang dikembangkan. 

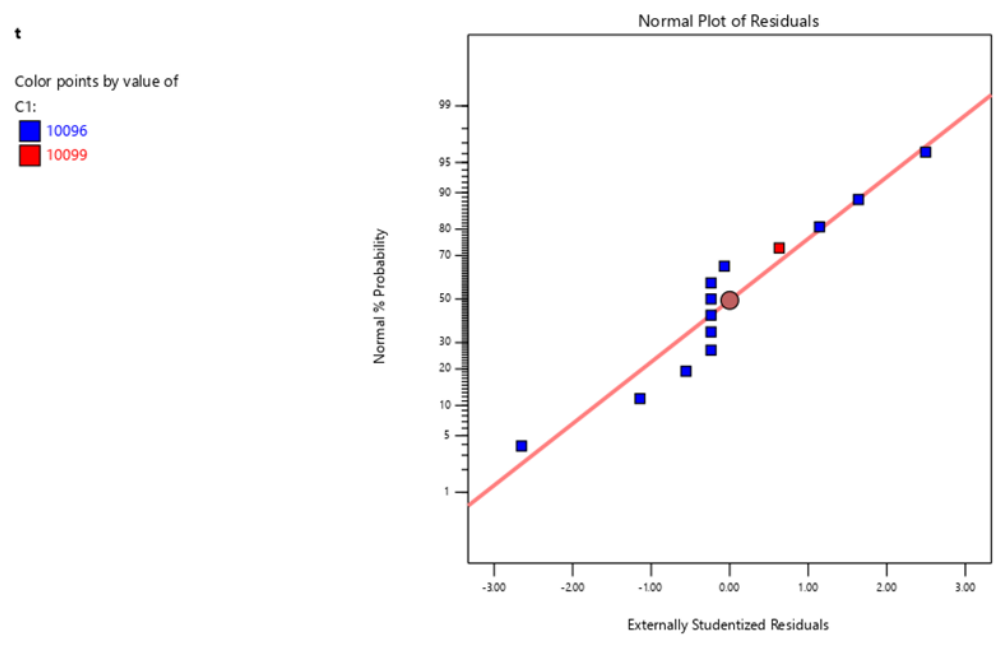

Gambar 5 Grafik Plot Residual Waktu

Model menunjukkan koefisiensi determinasi yang cukup tinggi $\left(\mathrm{R}^{2}\right.$ 0,9799) dan koefisien determinasi terkoreksi juga tinggi (adj. $\left.R^{2} 0,9979\right)$. Hal ini mengindikasikan bahwa lebih dari $98 \%$ data eksperimen bersesuian dengan hasil prediksi oleh model dan hanya kurang dari $2 \%$ total variasi yang tidak dapat dijelaskan oleh model. Namun jika pada sebuah model terdapat banyak nilai eksperimen yang dihasilkan tidak besar maka $\mathrm{R}^{2}$ yang terkoreksi jelas akan lebih kecil dari $\mathrm{R}^{2}$. Pada kasus ini nilai $\mathrm{R}^{2}$ terkoreksi (adj. $\mathrm{R}^{2}$ ) lebih rendah dari $\mathrm{R}^{2}$ Sehingga hasil anova pada Response Surface Methodologi tersebut diplotkan menjadi grafik 3D Surface seperti pada Gambar 5.

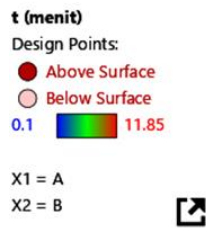

[

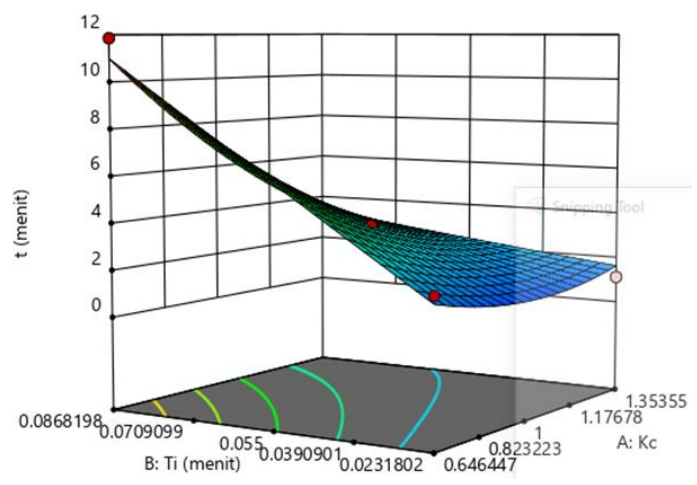

Gambar 6 Model Grafik 3D Surface Untuk Variabel Time RSM 1 
Gambar 6 menunjukkan titik optimum time (y) dari interaksi Ti (xi) dan Kc (x2). Titik optimum interaksi tersebut di dapat pada $\mathrm{Kc}=1$ dan $\mathrm{Ti}=$ 0.01 maka waktu yang diperoleh adalah menit dan titik minimum yang diperoleh $\mathrm{Kc}=1$ dan $\mathrm{Ti}=0.02$ maka time (menit) yang diperoleh adalah 0,1 menit.

Berdasarkan karakteristik dari control PI, apabila Kc terlalu kecil maka pengontrol proportional hanya mampu melakukan koreksi kesalahan hanyalah sebatas kesalahan kecil sehingga akan menghasilkan respon control yang lambat. Jika nilai Kc terlalu besar, maka akan respon tersebut tidak stabil dan berosilasi. Namun jika Ti terlalu besar, maka output akan berosilasi, dan pemilihan nilai Ti yang tidak tepat akan menyebabkan respon tidak bekerja atau respon transien sehingga terjadi ketidakstabilan sistem.

\section{Simpulan dan Saran}

Dapat disimpulkan bahwasanya Model Quadratic memberikan hasil yang mendekati data eksperimen, dari 3 model yang diuji, masing - masing model memberikan hasil prediksi mendekati data eksperimen sehingga mengindikasikan bahwa model ini sangat berpengaruh pada variabel terikat, Model menunjukkan koefisiensi determinasi yang cukup tinggi $\left(\mathrm{R}^{2} 0,98\right)$ dan koefisien determinasi terkoreksi juga tinggi (adj. $\mathrm{R}^{2}$ 0,99). Hal ini mengindikasikan bahwa lebih dari 98\% data eksperimen sesui dengan hasil prediksi. Pada pengujian menggunakan software Design Expert (RSM) didapatkan hasil tuning parameter terbaik pada $\mathrm{Kc}=1$ dan $\mathrm{Ti}=0,01$, Nilai Kc dan Ti merupakan factor yang paling berpengaruh terhadap respon waktu pada control PID. Waktu tercepat pada controller dalam merespon gangguan adalah tuning parameter terbaik pada $\mathrm{Kc}=1$ dan $\mathrm{Ti}=0.01$ untuk mengatasi gangguan sebesar 0,1 menit. Penggunaan cara bisectional pada model Design Expert X.13 (Response Surface Methodology) terbukti mampu menghasilkan hasil yang lebih rinci dalam mencari respon tercepat terhadap gangguan pada penelitian Pressure Control pada Outlet Gas. Berdasarkan penelitian yang dilakukan, sipenulis menyarankan kepada peneliti selanjutnya 
untuk menggunakan kombinasi RSM dan bisectional dalam penelitian sejenis dimasa mendatang.

\section{Daftar Pustaka}

1. Araki. (2002). PID Control. Edisi 1, Kyoto University, Japan

2. Damanik, I. Y., ZA, N., \& Muhammad, M. (2020). Optimasi Aplikasi Kontrol PI pada Tekanan di Continuous Stirred Tank Reactor (CSTR) menggunakan Response Surface Methodology (RSM). Jurnal Teknologi Kimia Unimal, Hal. 15-32. https://doi.org/10.29103/jtku.v8i2.2679

3. Haryono. (2007). Dasar Instrumentasi dan Proses Kontrol. In Direktorat Pengolahan Angkatan XVII, Balongan.

4. Heriyanto. (2010). Pengendalian Proses. Jurusan Teknik Mesin, Politeknik ITB, Bandung.

5. Julie Levine, G. D. (2013). Chemical Process Principles. Jump Start: Aspen HYSYS ® Dynamics V8.

6. Pratomo, V. A. (2012). Perancangan Pengendali Pid Pada Pressure Process Rig ( 38-714 ) Berbasis Mikrokontroller E (S), Jurnal Teknik Ftup Volume 25 Nomor 2 Juni, Hal.106-113.

7. Skogestad, S., \& Grimholt, C. (2011). The SIMC method for smooth PID controller tuning. Process Control, Skogestad, Hal.1-29.

8. Taryono, O. (2009). Aplikasi HYSYS Dynamic untuk Process Control. Jakarta.

9. Astrom,K.andHagglund,T.(1995).PIDControllers:theory,designandtuning.I SAPress,ResearchTrianglePark,London. 